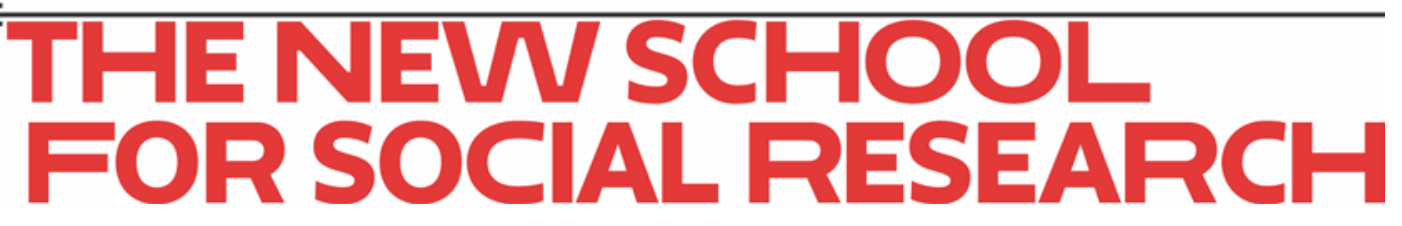

Mark Setterfield and Selen Ozcelik

\title{
Is the balance of payments constrained growth rate time-varying? Exchange rate over valuation, policy-induced recessions, deindustrialization, and long run growth
}

August 2017

Working Paper 26/2017

Department of Economics

The New School for Social Research 


\title{
Is the balance of payments constrained growth rate time-varying? Exchange rate over valuation, policy-induced recessions, deindustrialization, and long run growth*
}

\author{
Mark Setterfield ${ }^{\dagger}$ and Selen Ozcelik ${ }^{\ddagger}$
}

August 21, 2017

\begin{abstract}
A long-held view among macroeconomists in the UK and US is that sustained currency over valuation - often the result of financial-sector dominance - weakens domestic macroeconomic performance and results in premature deindustrialization. Similar concerns have been expressed about persistent, policy-induced recessions. According to balance-of payments-constrained growth (BPCG) theory, meanwhile, the BPCG rate in a multi-sector economy varies directly with the share of manufacturing in total output. This chapter develops a simple model that combines these observations to show how a temporary but persistent shock to the nominal exchange rate and/or domestic demand can both affect the actual rate of growth in the short run (by moving it away from the long-run equilibrium BPCG rate), and alter the BPCG rate itself (by lowering the income elasticity of demand for exports as a result of induced premature deindustrialization). The result is a time-varying balance-of payments constrained growth (TV-BPCG) rate. Because actual growth and the TV-BPCG rate vary directly, the latter is also characterized as quasi path dependent.
\end{abstract}

JEL codes: E12, F43, O41

Keywords: Exchange rate, policy-induced recession, deindustrialization, balance-ofpayments-constrained growth, path dependence

*Paper in preparation for P. Arestis (ed.) Alternative Approaches in Macroeconomics: Essays in Honour of J.S.L. McCombie, Palgrave Macmillan, forthcoming.

†New School for Social Research; email mark.setterfield@newschool.edu.

${ }^{\ddagger}$ New School for Social Research; email ozces608@newschool.edu. 


\section{Introduction}

At least since Singh (1977), macroeconomists have expressed concern with "premature deindustrialization" - a decline in the manufacturing share of economic activity in advance of that associated with established secular trends towards tertiarization in capitalist economies $\mathrm{H}^{1}$ Concern with premature deindustrialization in advanced capitalist economies has long since extended to the notion that such failure may not be endemic to the manufacturing sector itself, but may instead be policy induced. Persistent exchange rate over valuation, for example, may reduce the cost-competitiveness of the manufacturing sector in international trade, resulting in the sector's contraction (Blecker, 2003; Hersh, 2003; Palley, 2003, 2016) 2 Prolonged recessions, meanwhile - which may be policy induced - are understood to disproportionately affect the cyclically-sensitive manufacturing sector, reducing the share of manufacturing in overall activity (see Rowthorn and Wells (1987, pp.??); Uemura and Tahara (2015)). Recessions may also retard induced productivity growth in manufacturing (via Verdoorn's law), reducing either the price or non-price competitiveness of manufactured tradables, and so inducing further shrinkage of the manufacturing sector.

This chapter integrates concern over premature deindustrialization into balance-of-paymentsconstrained growth (BPCG) analysis, one of the major contemporary currents in Kaldorian growth theory, to which John McCombie has been such an important contributor for over 35 years. The basis for what follows is the multi-sector BPCG model of Araujo and Lima (2007). We build on this contribution to develop a theory of a time-varying balance-of payments-constrained growth (TV-BPCG) rate, in which the standard multi-sector BPCG rate is rendered time varying by virtue of temporary but persistent currency over-valuations

\footnotetext{
${ }^{1}$ See, for example, Rowthorn and Wells (1987) on the so-called "maturity effect" - a process of deindustrialization that appears to be an inevitable accompaniment of the growth trajectory of advanced capitalist economies.

${ }^{2}$ This is sometimes interpreted as part of a larger set of concerns regarding "finance versus industry" in modern capitalism (Epstein and Schor, 1990, Epstein, 2001).
} 
and/or policy-induced recessions that retard the actual rate of growth in the short run. These developments also induce structural change - specifically, premature deindustrialization - that affects the value of the long-run equilibrium BPCG rate $3^{3}$ Since the BPCG rate thus varies with the short run growth rate (by virtue of the sensitivity of both to currency over valuations and/or policy-induced recessions), the TV-BPCG rate so-derived can be interpreted as quasi path dependent. The results of these theoretical extensions to the canonical multi-sector BPCG model are also shown to give rise to a new empirical agenda for BPCG analysis.

The remainder of the chapter is organized as follows. Section 2 establishes the link between exchange rate fluctuations, recessions, and premature deindustrialization. In section 3 we develop an extended BPCG model that demonstrates how the events discussed in section 2 can affect long-run growth. Section 4 reflects on the implications of the resulting TV-BPCG model, and section 5 concludes.

\section{Currency over valuation, recessions, premature dein- dustrialization, and BPCG analysis}

In the Thirlwall's law literature, the role of relative prices and hence price competitiveness in determining the long run BPCG rate is generally disregarded, since the price elasticities of imports and exports are assumed to be very small (so-called elasticity pessimism). On that account, variations in the exchange rate - the domestic price of foreign currency - are considered to have no effect on long run growth (Thirlwall, 1979). Nevertheless, if an economy

\footnotetext{
${ }^{3}$ Overall, then, our basic approach is not unlike that of Missio et al. (2017), who also build on the multisector BPCG model of Araujo and Lima (2007) to show that an exchange rate devaluation can affect the BPCG rate by (inter alia) increasing the manufacturing share of economic activity. Unlike Missio et al. (2017), however, who consider the comparative static effects of the exchange rate on the equilibrium rate of growth, the model developed here captures the permanent effects (on the BPCG rate) of a transitory exchange rate appreciation. It also shows how an explicitly transitory shock to domestic demand can be interpreted as having the same (long run equilibrium growth retarding) effect.
} 
is considered within a multi-sectoral framework, variations in the exchange rate may have an impact on the income elasticity of exports if exchange rate variations disproportionately affect the manufacturing and non-manufacturing sectors which, in turn, account for different shares of total tradable goods and services. In this way, variations in the exchange rate, together with any other causes of structural change that alter the relative shares in activity of the manufacturing and non-manufacturing sectors, may have long run consequences for domestic macroeconomic performance. Put differently, deindustrialization and its causes appear as important phenomena to investigate in BPCG analysis.

Deindustrialization is commonly defined as a decline in the relative share of employment in the manufacturing sector ${ }^{\mathbb{4}}$ There are known to be different paths towards deindustrialization, however. The most common path is positive deindustrialization due to the maturity effect (Rowthorn and Wells, 1987). This occurs when advanced countries experience a decline in the relative share of manufacturing employment as a consequence of high productivity growth in the manufacturing sector, so that they no longer need to maintain the manufacturing share of employment to keep up the same share of manufacturing in total output. In this case, unemployment need not occur because job opportunities in slow productivity growth (and therefore labour absorbing) non-manufacturing industries allow workers to shift between sectors. This type of deindustrialization is symptomatic of economic success $5^{5}$

Nonetheless, countries may experience premature deindustrialization because of currency over valuations and/or policy-induced recessions. Recessions that cause a reduction in investment spending and productivity growth in the manufacturing sector or persistent currency over valuations that diminish the competitiveness of manufacturing industries can reduce the manufacturing share of output and employment and also harm aggregate economic per-

\footnotetext{
${ }^{4}$ The manufacturing share of total output is also sometimes used to gauge deindustrialization. See, for example, Felipe and Mehta (2016) for a recent discussion of international trends in the manufacturing share of total output.

${ }^{5}$ It may not be altogether benign, however, since stagnant service-sector productivity growth may contribute to stagnant real wage growth in this sector, and hence rising income inequality.
} 
formance in the short run. But the detrimental effects of such events may not remain limited to the short run. Even temporary variations in domestic demand and/or the exchange rate may have lasting consequences for domestic macroeconomic performance via their impact on the manufacturing sector.

According to Kaldor's first law, the manufacturing sector is the engine of growth performance in an economy, since this sector has higher productivity growth than the nonmanufacturing sector (Kaldor, 1960) $!^{6}$ Higher productivity growth ensures higher non-price competitiveness and hence a higher income elasticity of demand for exports - a parameter that is central to the determination of the BPCG rate. Moreover, through spillover effects and complementarity, the success of the manufacturing sector feeds into improved non-manufacturing sector performance in terms of employment and productivity. When the share of the manufacturing sector declines as a result of exchange rate appreciations and/or policy-induced recessions, the result is premature or negative deindustrialization that is not caused by the maturity effect and economic success but by economic (including policy) failure.

As experienced in the UK during the 1970s and in the US during the 1990s, recessionary conditions and/or currency over valuation may result in the loss of manufacturing capacity (as opposed to just a fall in the capacity utilization rate) due, in the first instance, to declining domestic and international demand. This process may be self-perpetuating due to Verdoorn's Law, which describes productivity growth as depending on the manufacturing growth rate and highlights the important influence of demand on supply conditions. As productivity growth slows, a country's manufacturing sector loses both its price and non-price competitiveness compared with its rivals in international trade inducing a further worsening of macroeconomic performance. Once the manufacturing sector is damaged, moreover,

\footnotetext{
${ }^{6}$ See Thirlwall (1983) on Kaldor's laws and Cantore et al. (2017) for a review of, and further contribution to, recent empirical evidence affirming the importance of Kaldor's first law.
} 
restoring the sector to health is far from a simple task. Blecker (2003) summarizes the cost of dollar over valuation beginning in the late 1990's for the US manufacturing sector. According to Blecker, increasing the value of the dollar relative to the euro and other major currencies of countries that have strong trade relations with the US (such as Japan and China) affected domestic manufacturing sector through employment, profit, and investment spending channels. When the US dollar appreciated, export growth slowed resulting in a negative net effect on employment, with 740000 jobs lost in the manufacturing sector by 2002. Moreover, loss of trade resulted in lower profit for manufacturing firms, reducing their willingness to invest and depriving them of the necessary financial resources to fund planned investment spending. As a result, the US manufacturing sector lost $\$ 100$ billion dollar in annual profits and experienced a decline of over $\$ 40$ billion annually in investment spending (corresponding to 25\% of total US manufacturing investment ) through 2002 (Blecker, 2003). Meanwhile, according to Rowthorn and Wells (1987), when Britain went through recession during the early 1970's, followed by the sudden sterling appreciation after 1977, and then experienced the Thatcher government's deflationary policies designed to control inflation following the second oil crisis, the British manufacturing sector was severely harmed. Even though the combination of recessionary conditions and over valuation came to an end after 1982, complete recovery of the manufacturing sector could not be achieved (Rowthorn and Wells, 1987, pp.136-7).

\section{The model}

In this section, we use the insights discussed in the previous section to develop an extended BPCG model that shows how temporary but persistent recessions and/or exchange rate over valuations can induce premature industrialization and so reduce the long-run equilibrium BPCG rate. 


\subsection{A multi-sector BPCG model}

The canonical BPCG model is a demand-led, one-sector aggregate structural model based on a single (tradable) commodity. Kaldorian growth theory, however, suggests that economic growth depends (in part) on the sectoral composition of output. This is because of the dynamic properties of the manufacturing sector, which is seen as the engine of growth.7 It is not surprising to find, therefore, that multi-sector variants of BPCG theory have emerged that, while continuing to emphasize the importance of demand, also emphasize economic structure as a fundamental driver of growth Nell, 2003; Araujo and Lima, 2007, Razmi, 2011; Nishi, 2016).

The essence of the multi-sector approach to BPCG theory can be represented using a simplified version of (Araujo and Lima, 2007) model as follows. Consider an economy that imports a single commodity (denoted $M)$, but exports a mixture of manufacturing $(m f)$ and non-manufacturing $(\mathrm{nmf})$ goods in proportion to its domestic industrial structure. The total value of exports can be described as:

$$
P X=P_{m f} X_{m f}+P_{n m f} X_{n m f}
$$

where $P$ and $X$ can be thought of as composite indices of the domestic price and volume of exported goods, respectively, $P_{m f}$ and $P_{n m f}$ are the domestic prices of manufactures and non-manufactures, respectively, and $X_{m f}$ and $X_{n m f}$ denote the volume of manufactured and non-manufactured exports, respectively. This expression can be re-written as:

$$
X=\frac{P_{m f}}{P} X_{m f}+\frac{P_{n m f}}{P} X_{n m f}
$$

\footnotetext{
${ }^{7}$ See, for example, Thirlwall (2013) for a recent discussion these basic tenets of Kaldorian growth theory - and in particular, the importance of both demand and economic structure in the determination of long-run growth - in the context of BPCG theory.
} 
Assuming that the relative prices of exports remain constant in the long run 8 it follows that:

$$
x=\omega_{m f} x_{m f}+\left(1-\omega_{m f}\right) x_{n m f}
$$

where lower case variables represent proportional rates of growth and $\omega_{m f}$ is the share of manufacturing activity in the domestic economy (and hence, by assumption, in total exports).

Suppose now that import and export demand can be written as:

$$
M=\left(\frac{P_{f} E}{P}\right)^{\psi} Y^{\pi}
$$

where $P_{f}$ is the foreign price of the imported commodity, $M$ is the volume of imports, and $E$ is the nominal exchange rate, and $\psi$ and $\pi$ are the price and income elasticities of demand for imports, respectively, and:

$$
X_{i}=\left(\frac{P_{i}}{P_{f} E}\right)^{\phi_{i}} Z^{\rho_{i}} \quad, \quad i=m f, n m f
$$

where $\phi_{i}$ and $\rho_{i}$ are the price and income elasticities of exports, respectively. Assuming constancy of relative prices in a common currency, it follows that:

$$
m=\pi y
$$

and:

$$
x_{i}=\rho_{i} z \quad, \quad i=m f, n m f
$$

from which (by substituting (7) into (3)) we arrive at:

\footnotetext{
${ }^{8}$ This assumption is a counterpart to the assumption of a constant real exchange rate from which the canonical one-sector version of Thirlwall's Law can be derived.
} 


$$
x=\left[\omega_{m f} \rho_{m f}+\left(1-\omega_{m f}\right) \rho_{n m f}\right] z
$$

Finally, we can write the aggregate balance-of-payments constraint on growth as:

$$
P_{f} M E=P X
$$

Once again assuming constancy of relative prices in a common currency (in this case, a constant real exchange rate, so that $p_{f}+e-p=0$ ) we get:

$$
m=x
$$

Substituting equations (6) and (8) into equation (10) and solving for $y$ we arrive at:

$$
y_{B}=\frac{\left[\omega_{m f} \rho_{m f}+\left(1-\omega_{m f}\right) \rho_{n m f}\right] z}{\pi}
$$

In equation (11), $y_{B}$ is the long run equilibrium (balance-of-payments-constrained) growth rate. Note that, from (11), it follows that:

$$
\frac{d y_{B}}{d \omega_{m f}}=\frac{\left(\rho_{m f}-\rho_{n m f}\right) z}{\pi}>0
$$

if, as is assumed here, $\rho_{m f}-\rho_{n m f}>0$. This latter inequality implies that world income growth is disproportionately directed towards growth in demand for manufactures. Its impact on the sign of the derivative in equation (12) is in keeping with the Kaldorian disposition to regard the manufacturing sector as the engine of growth (Kaldor's first law). Hence according to (12), the greater the manufacturing content of domestic output (and hence exports), the higher the long run equilibrium BPCG rate, $y_{B}$. 


\subsection{Policy induced recessions, exchange rate over valuation and growth: A baseline model}

Suppose initially that we take $\omega_{m f}$ as given, so that we can write:

$$
y_{B}=\frac{\left[\bar{\omega}_{m f} \rho_{m f}+\left(1-\bar{\omega}_{m f}\right) \rho_{n m f}\right] z}{\pi}=\bar{y}_{B}
$$

Now consider an extension of the model developed in the previous sub-section, such that:

$$
\begin{gathered}
y=y_{B}+\delta\left(E-E^{*}\right) \\
E=E^{*}+\epsilon \\
\epsilon=\alpha \epsilon_{-1}+\eta
\end{gathered}
$$

where $\eta \sim\left(0, \sigma_{\eta}^{2}\right), y$ is the short-run rate of growth, and $E^{*}$ is a constant short-run value of the nominal exchange rate that, within a particular short period, is consistent with the constant real exchange rate used to derive equation (11) .9 Equation (14) states that the short run rate of growth can depart from the long run equilibrium BPCG rate if the nominal exchange rate is over- or under-valued $\left(E \neq E^{*}\right)$. Equations (15) and (16), meanwhile, describe such misalignments as arising from persistent shocks. Note that the analytical framework in equations (13) through $(16)$ permits reinterpretation of $E^{*}$ as the value of policy-sensitive domestic components of aggregate demand that is consistent with the long run equilibrium $\mathrm{BPCG}$ rate, $y_{B}$, so that $E \neq E^{*}$ can also be thought of as representing policy induced, domestic-demand-led booms or recessions that cause the short-run rate of growth to depart from its long run equilibrium value.. In this way, under the same analytical

conditions $\left(\eta<0 \Rightarrow \epsilon<0 \Rightarrow E<E^{*}\right)$, equations (13) through (16) can be interpreted as

\footnotetext{
${ }^{9}$ Long run constancy of the real exchange rate does not require long run constancy of the nominal exchange rate, but we assume here that, for discrete intervals of time, the (own currency) prices of tradable goods are fixed so that there exists, in the short run, a unique constant value of $E$ consistent with long run constancy of the real exchange rate.
} 
representing the effects on short-run growth (relative to its long-run equilibrium value) of either a persistent currency over valuation or a persistent policy-induced recession.10

Combining (13) through (16) yields:

$$
y=\bar{y}_{B}+\delta \alpha^{t-1} \eta
$$

Suppose now that with $y=\bar{y}_{B}$ initially, $\eta<0$ in some period $t=1$. The resulting trajectories of $y$ (in accordance with (17)) and $y_{B}$ (in accordance with (13) ) are illustrated in Figure 1. As might be expected, $y$ departs from the constant $\bar{y}_{B}$ in accordance with the initial shock, subsequently converging back to $y=\bar{y}_{B}$ at a rate determined by $\alpha$ (which captures the degree of persistence in the initial shock). Although the short-run rate of growth is adversely affected - which adverse effect is increasing in the size of $\alpha$ - the long-run equilibrium rate of growth is unaffected.

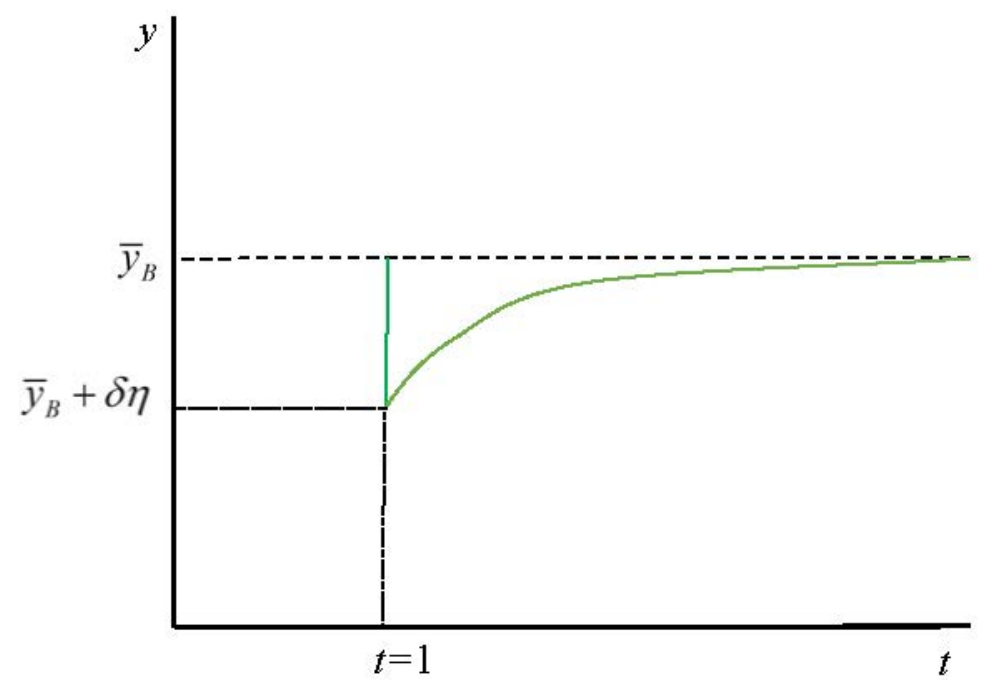

Figure 1: Response of growth to a persistent shock in the baseline model

\footnotetext{
${ }^{10}$ Recall that as defined in equations $(4)$ and $(5), E$ is the domestic price of foreign currency, so that a fall in the value of $E$ such that $E<E^{*}$ represents a nominal exchange rate appreciation.
} 


\subsection{Policy induced recessions, exchange rate over valuation and growth: an extended model with premature deindustrializa- tion}

Now suppose that we retain (14) through (16), but relax the assumption of a constant $\omega_{m f}$ and, in keeping with the results in (11) and (12), replace (13) with:

$$
y_{B}=f\left(\omega_{m}\right) \quad, \quad f^{\prime}>0
$$

and:

$$
\dot{\omega}_{m}=\beta\left(E-E^{*}\right) \quad, \quad \beta>0
$$

Equation (18) is merely an implicit version of equation (11), while equation (19) endogenizes the manufacturing share of activity. Specifically, (19) suggests that the manufacturing share varies over time in accordance with $E \neq E^{*}$. With $\beta>0$, this captures the possibility that either exchange over valuation or policy-induced recessions $\left(E<E^{*}\right)$ can induce premature deindustrialization.

The effects of equation (19) on the behaviour of the system can be described as follows. First, note that it follows from (18) that $\dot{y}_{B}=f^{\prime} \dot{\omega}_{m}$. Combining this last expression with (19), we arrive at:

$$
\dot{y}_{B}=f^{\prime} \beta\left(E-E^{*}\right)
$$

Combining (20) with (15) and (16), re-writing 17 to take into account time-variation in the BPCG rate, and treating $\dot{x} \sim x_{t}-x_{t-1}$ for any $x$, we arrive at:

$$
\begin{gathered}
y_{B t}=y_{B t-1}+f^{\prime} \beta \alpha^{t-1} \eta \\
y_{t}=y_{B t}+\delta \alpha^{t-1} \eta
\end{gathered}
$$

Now assume that $f^{\prime} \beta<\delta$ - in other words, any $\eta<0$ initially will cause a larger drop in $y$ 
than in $y_{B}$. This is because while it is reasonable to assume that the actual rate of growth will respond immediately to exchange rate appreciation or domestic demand deflation, the sensitivity of the long run equilibrium BPCG rate to these same conditions will take time to gradually become manifest, working as it does through channels that involve structural change in the economy.

Suppose now that $\eta<0$ in some initial period $t=1$. The resulting trajectories of $y$ and $y_{B}$ consistent with 22) and 21, respectively, are illustrated in Figure 2. Once again, figure 2 depicts the immediate (negative) impact of $E<E^{*}$ on $y$, following which the actual rate of growth begins a process of convergence back towards its long-run equilibrium value at a rate determined by the magnitude of the persistence of the initial shock (the size of $\alpha$ ). This time, however, $E<E^{*}$ also causes an initial drop in the value of the long-run equilibrium BPCG rate itself, the latter continuing to decay as the shock persists. In other words, the persistence of the shock causes the long-run equilibrium growth rate to fall continuously, even as the actual rate of growth converges back towards its long-run equilibrium value. The traverse path so-described results (in the limit) in the economy settling into a new long run equilibrium BPCG rate at $y_{B}^{\prime}$ in figure 2. The sensitivity of the long-run growth rate to temporary (but persistent) exchange rate over valuation and/or policy-induced recessions is a product of the deindustrialization that these same conditions creates. The result as depicted in figure 2 - is variability over time in the BPCG rate, so that the long-run equilibrium rate of growth may now be described as a time-varying balance of payments constrained growth (TV-BPCG) rate.

To solve for the new long run equilibrium TV-BPCG rate depicted in figure 2, first note that it follows from equation (21) that:

$$
y_{B t}=y_{B 0}+f^{\prime} \beta \eta \sum_{i=1}^{t} \alpha^{t-i}
$$




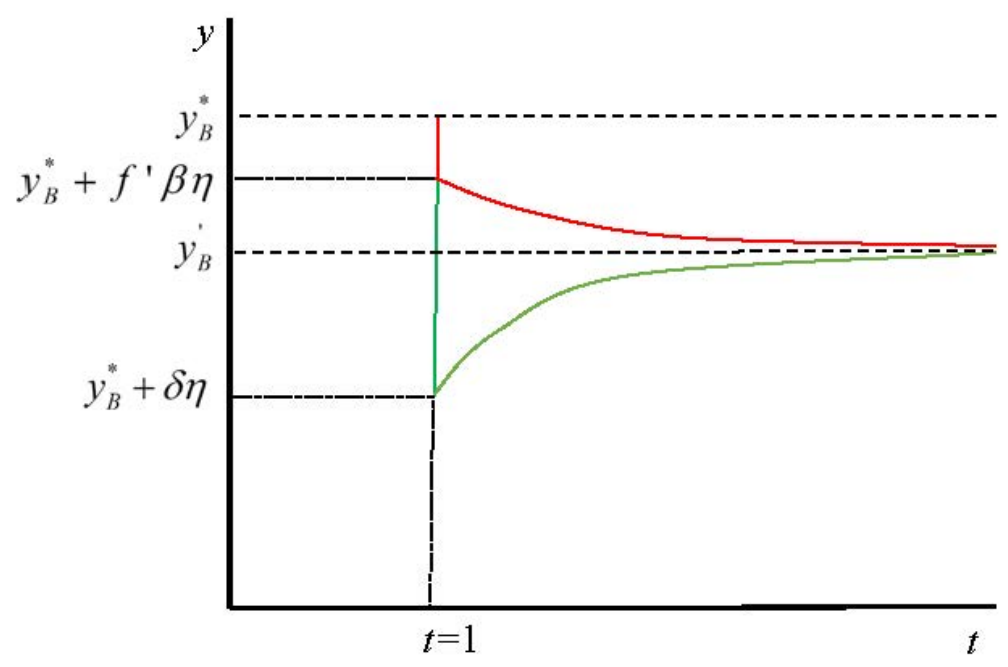

Figure 2: Response of growth to a persistent shock in the extended model

Substituting this expression into 22 we arrive at:

$$
y_{t}=y_{B 0}+\delta \alpha^{t-1} \eta++f^{\prime} \beta \eta \sum_{i=1}^{t} \alpha^{t-i}
$$

Note that:

$$
\lim _{t \rightarrow \infty} \delta \alpha^{t-1} \eta=0
$$

while:

$$
\lim _{t \rightarrow \infty} f^{\prime} \beta \eta \sum_{i=1}^{t} \alpha^{t-i}=\frac{1}{1-\alpha} f^{\prime} \beta \eta<0
$$

Recalling that $y_{B 0}=y_{B}^{*}$, it therefore follows from (23) that:

$$
\lim _{t \rightarrow \infty} y_{t}=y_{B}^{*}+\frac{1}{1-\alpha} f^{\prime} \beta \eta=y_{B}^{\prime}
$$


this last value being the new equilibrium TV-BPCG rate depicted in Figure 2.

\subsection{Simulations}

Having developed the TV-BPCG model in the previous sub-section, it is useful to show exactly how the system reacts to variations in $E$ (representing currency over valuations or policy-induced recessions) under different parameter restrictions. As can be inferred from equation (21), in addition to the initial value of the shock $\eta$ and the degree of persistence of this shock $(\alpha)$, how the long-run BPCG rate varies over time depends on the size of the parameters $\beta$ (the sensitivity of $\dot{\omega}_{m}$ to $E-E^{*}$, which we terms the "Palley effect") and $f^{\prime}$ (the sensitivity of $\dot{y}_{B}$ to $\dot{\omega}_{m}$, which we term the "Kaldor effect"). The size of these parameters may differ from country to country, subject to their precise economic structures. Keeping in mind that the exact values we assign to parameters (and to the initial values of variables) are arbitrary (the purpose of the exercise here being to assess the effect of increases or decreases in the size of parameters relative to a benchmark case, in the manner of a comparative static exercise), we can simulate different TV-BPCGs by assigning different values to the two key parameters $f^{\prime}$ and $\beta$ while keeping all other parameters constant. With this in mind, our basic parameter set (together with the initial values of the variables $\eta, y_{B}$, and $y$ ) is as follows:

- $y_{B 0}=y_{0}=5.0$;

- $\delta=0.1$

- $\alpha=0.8$; and finally

- $\eta_{0} \neq 0$, where the exact value of $\eta$ is determined by a random draw from a normal distribution with $\mu_{\eta}=-10$ and $\sigma_{\eta}=0.5$.

\footnotetext{
${ }^{11}$ Recall that $\delta$ captures the sensitivity of $y$ to $E-E^{*} \neq 0$ )
} 
In the first (benchmark) simulation, we assign values to our key parameters capturing the Palley and Kaldor effects of $\beta=0.2$ and $f^{\prime}=0.06$. The response of the system to a transitory shock $\eta_{0}<0\left(\eta_{i}=0 \quad \forall i \neq 0\right)$ is depicted in figure 3 .

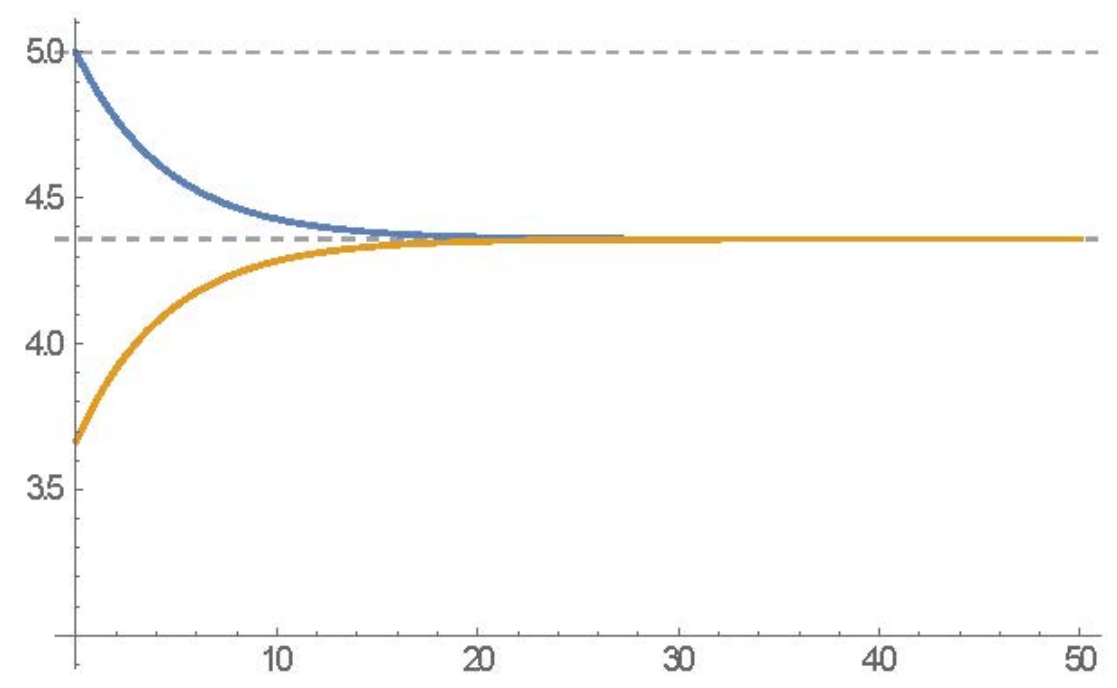

Figure 3: The Benchmark Case

In figure 3 , the blue line corresponds to the trajectory of the TV-BPCG rate $y_{B}$, and the yellow line depicts the trajectory of the actual growth rate $y \stackrel{12}{12}$ As can be seen, a temporary but persistent shock to $E$ results in a continuously falling long run BPCG rate. The shortrun actual growth rate, meanwhile, which deteriorates markedly more than the TV-BPCG rate in the immediate aftermath of the shock, subsequently reverts towards the declining TV-BPCG rate, the two growth rates eventually converging towards a new, lower, long run equilibrium growth rate. This benchmark simulation replicates the system dynamics depicted in figure 2, where the short-term effects of the shock $\eta \neq 0$ on growth are larger than the long-term effects, but the latter are relatively large (the TV-BPCG falling from an initial value of $5.0 \%$ to about $4.4 \%)$.

\footnotetext{
${ }^{12}$ The same conventions are maintained throughout the simulations that follow.
} 
Our next simulation depicts a case involving smaller Palley and Kaldor effects, reflected in the smaller parameter values $\beta=0.1$ and $f^{\prime}=0.03$. The results of this second simulation are depicted in figure 4 .

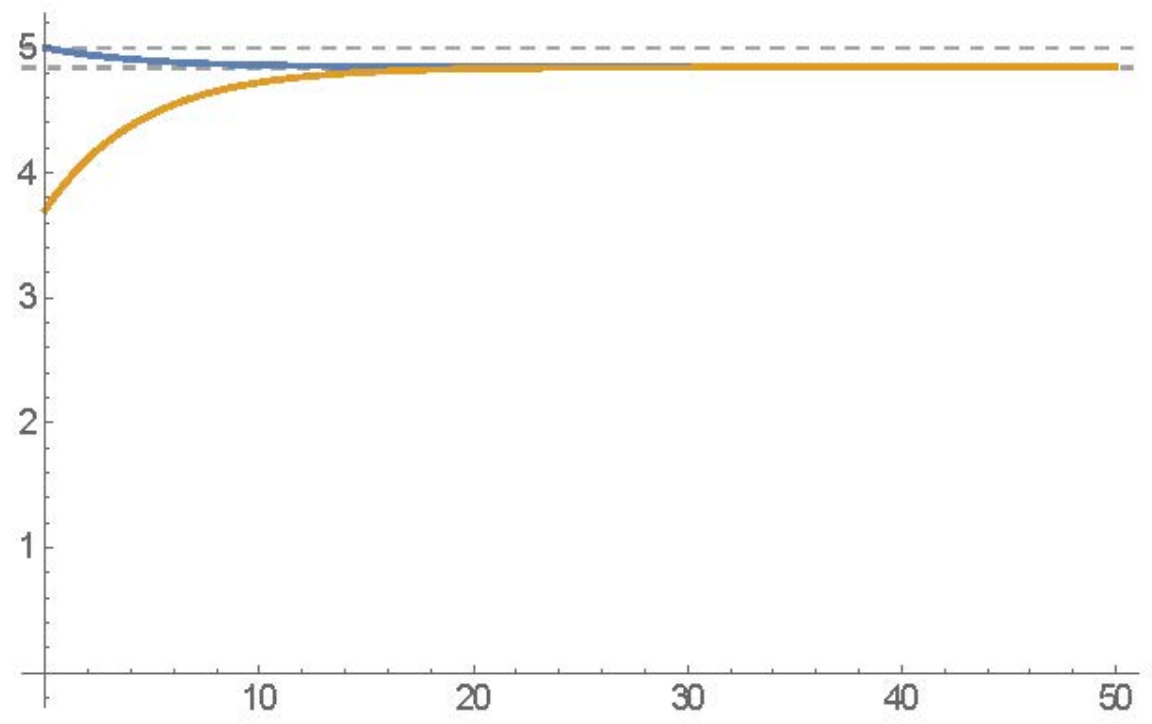

Figure 4: A Less Shock-Prone TV-BPCG Rate

Here, the system dynamics display a similar pattern to those observed in the benchmark case depicted in figure 3. But the impact on long run growth is much reduced, the new steady state being only marginally lower than its original $5 \%$ value. This is because neither the sensitivity of the manufacturing share to exchange rate appreciation/domestic demand deflation (the Palley effect) nor the sensitivity of the long run growth rate to the manufacturing share (the Kaldor effect) are large enough to create major changes in the TV-BPCG rate. This pattern may be observed in countries which have relatively higher income elasticities of demand for their manufacturing exports compared to their trade rivals, as a result of firms' efforts to increase non-price competitiveness, so that a shock to the exchange rate that has detrimental effects on price competitiveness results only in slight declines in the manufacturing sector and hence the TV-BPCG rate. Moreover, as a result of 
positive de-industrialization and/or industrial policy, both the income elasticity of demand for non-manufacturing exports and the share of the non-manufacturing sector in exports may be high. At the same time, spill-over effects from a robust manufacturing sector to the non-manufacturing sector may result in enhanced productivity performance in this sector (at least among what Baumol et al. (1991) term "dynamic" service industries that are less prone to Baumol's disease), as a result of which certain non-manufacturing industries share (with the manufacturing sector) the role of "engine of growth". In other words, with smaller Palley and Kaldor effects (smaller values of $\beta$ and $f^{\prime}$, respectively) the time variance of the BPCG rate may be relatively minor and, as a consequence, the TV-BPCG rate will be less shock-prone.

In our final simulation, we depict an extreme case involving larger Palley and Kaldor effects captured by the parameter values $\beta=0.3$ and $f^{\prime}=0.3$ (see figure 5). In this case, the actual growth rate and the BPCG rate eventually collapse to a new steady state growth rate of less than $1 \%$, far below the initial equilibrium growth rate of $5 \%$.

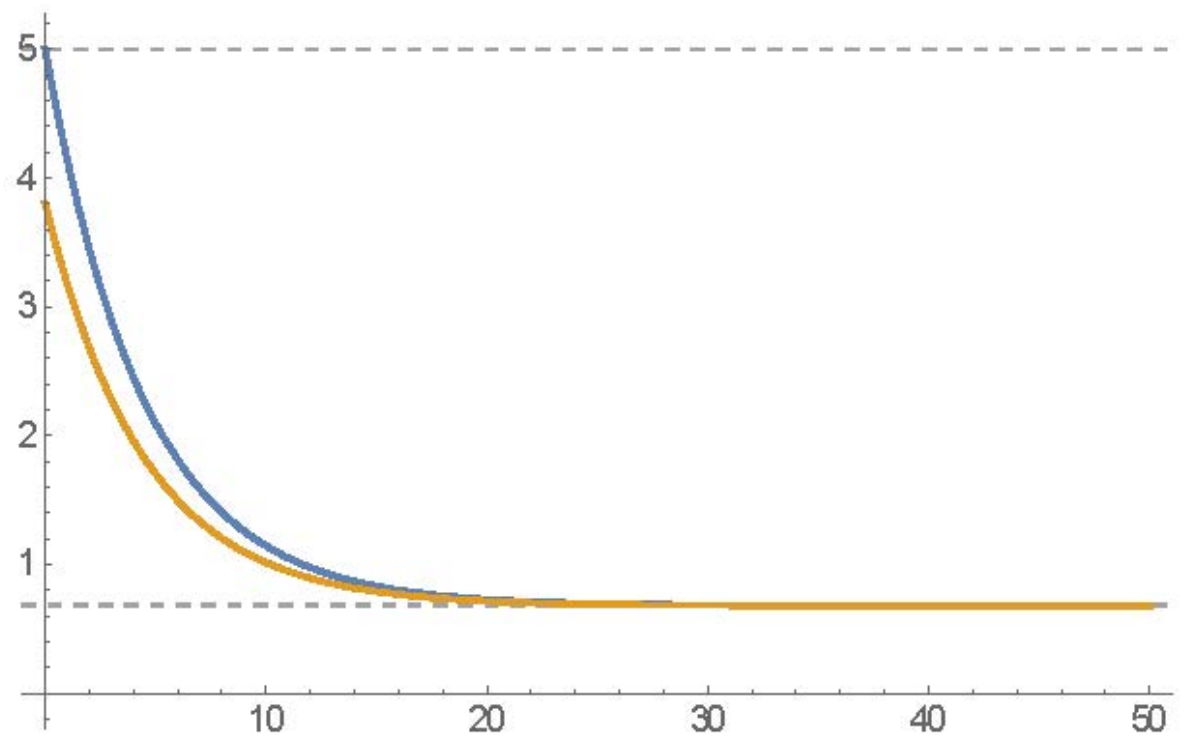

Figure 5: The Damaging Consequences of Large Palley and/or Kaldor Effects 
As seen in figure 5, either one or both of the Palley and Kaldor effects can be so large as to be overwhelming, producing extreme sensitivity of $y_{B}$ to the initial shock $\eta_{0} \neq 0$. In this case, the initial drop in the short-term actual rate of growth $y$ due to $\eta_{0} \neq 0$ causes a subsequent drop in $y_{B}$ that - due to the Palley and Kaldor effects - is so large that the properties of $y_{B}$ as an attractor subsequently pull $y$ down further below its initial depressed value. The end result is that both $y$ and $y_{B}$ continue to fall as the initial shock persists, eventually converging to a new steady state value that lies below $y_{0}+\eta_{0}$ (where $\eta_{0}<0$ ). In other words, the long-term growth effects of a persistent demand shock are now larger than the short-term effects.

The simulation exercises above demonstrate the sensitivity of the TV-BPCG, in an economy subject to transitory but persistent demand shocks, to differing magnitudes of the Palley effect (the sensitivity of the manufacturing share to exchange rate over valuation and/or domestic recessions) and the Kaldor effect (the extent to which manufacturing is the engine of long run growth). In so doing, they draw attention to the way in which negative deindustrialization caused by recessions and/or exchange rate over valuation may impact economic structure in such a way as to lower the long-run equilibrium BPCG rate. Note that if $E \neq E^{*}$ due to the side-effects of policy (e.g., a high interest rate regime designed to curb inflation), then ultimately the outcomes reflected in the TV-BPCG rate are also policy side-effects. These adverse consequences for growth are long-term and (ceteris paribus) permanent, but it cannot be argued that they result from policy lock in/out (as in Palley (2016), since $E=E^{*}$ in the long run (in Palley's terms, policy can be, and eventually is, "dialed back"). But economic structure is nevertheless affected with detrimental long-run macroeconomic performance effects, revealing that permanent damage can be wreaked by even temporary policy mistakes (such as the "Thatcher experiment" with monetarism) that are not subject to policy lock in. 


\section{A time-varying and quasi path dependent balance of payments constrained growth rate}

The behaviour of $y$ and $y_{B}$ resulting from equations 22 and (21) gives rise to a longrun equilibrium BPCG rate that is time-varying, as in equation (24). The obvious contrast is with orthodox BPCG theory, as summarized (in the case of a multi-sector economy) by equation (11). Here, the BPCG rate is understood as a single-valued steady state that, in the absence of exogenous parametric change, remains constant in the long run and unaltered by short-term adjustment dynamics that lead the actual rate of growth back towards the BPCG rate in the event of a transitory disequilibrating shock (see, for example, McCombie and Thirlwall (1994); McCombie (2011); Setterfield (2011); Thirlwall (2011).

In fact, with $y \neq y_{B}$ in the short-term now resulting in permanent change in $y_{B}$ in the long run, equations 22 and (21) resemble a path-dependent system wherein any (on the face of it, temporary) change in the actual rate of growth results in change in the long-run equilibrium rate of growth 13 This appearance of path dependence should not be exaggerated, however. As the analysis in sub-section 3.3 makes clear, a common third factor - the sensitivity of both $y$ and $y_{B}$ to $E \neq E^{*}$ - is driving the behaviour of the system as a whole. Nevertheless, it might be said that $y_{B}$ is not only time-varying, but also quasi path dependent.

Both the theoretical development of a TV-BPCG rate and its identification as quasi path dependent are potentially exploitable in an empirical context. Consider first the existence of a TV-BPCG rate. If we think of $y_{B}$ as the low-frequency trend in an economy's real output growth time series data, then any evidence of the non-constancy of this trend would substantiate the hypothesis that there exists a TV-BPCG rate. For instance, rejection of

\footnotetext{
${ }^{13}$ Indeed, the results derived from equations 22 and 21 might even be described as hysteresis-like, in the sense that they describe a strictly transitory shock as ultimately having permanent effects on the growth path of the economy. We refer to a "hysteresis-like" result here by virtue of its having one of the salient properties of hysteresis - namely, the propensity of a temporary cause to have a permanent effect. Note, however, that it does not arise from a process of "strong" or "true" hysteresis. See Setterfield (2009) for further discussion.
} 
the null hypothesis that the trend in an economy's real output growth time series data is I(0) would provide prima facie evidence of the existence of a TV-BPCG rate.

Consider now the value of identifying the TV-BPCG rate as quasi path dependent to BPCG empirics. Having already interpreted $y_{B}$ as the low-frequency trend in an economy's real output growth time series data, it is reasonable to think of the accompanying highfrequency cyclical component of the same data as representing $y \neq y_{B}$ as a result of $E \neq$ $E^{*}$. The quasi path dependence of the TV-BPCG rate now suggests that there is merit to studying the sensitivity of the trend to the cyclical component of real output growth data. The methodology for such analysis has already been established in the NAIRU literature and has since migrated to Post-Keynesian macrodynamics (Schoder, 2012).

In sum, while this chapter has focused on developing the theory of a TV-BPCG rate, the analysis presented has clear empirical extensions. The TV-BPCG rate (interpreted as the trend component of time series growth rate data) can be expected to vary with the short run growth rate (the cyclical component of time series growth rate data), as a result of its quasi path dependence. This is suggestive of a new empirical agenda in BPCG analysis that focuses on studying the time variation in and quasi path dependence of the BPCG rate.

\section{Conclusions}

Multi-sector BPCG models emphasize the importance of economic structure (as well as demand) for long run growth, in keeping with Kaldor's first law. Analysis of structural change, meanwhile, suggests that premature deindustrialization can be induced by persistent currency over valuations and/or recessions - either of which may be a by-product of macro policy. This chapter combines these insights to develop a model of time-varying balance-ofpayments-constrained growth (TV-BPCG). The TV-BPCG rate is shown to be quasi path dependent, suggesting a new empirical agenda for BPCG analysis associated with trend-cycle interactions in time-series growth data. It is hoped that these insights will contribute to the 
further advancement of BPCG theory and Kaldorian growth theory writ large and that in so doing, they pay fitting tribute to the foundational work of John McCombie in this field.

\section{References}

Araujo, R. A. and G. T. Lima (2007). A structural economic dynamics approach to balanceof-payments-constrained growth. Cambridge Journal of Economics 31 (5), 755-774.

Baumol, W., S. Blackman, and E. Wolff (1991). Productivity and American Leadership: The Long View. Cambridge, MA: MIT Press.

Blecker, R. (2003). The benefits of a lower dollar: How the high dollar has hurt U.S. manufacturing producers and why the dollar still needs to fall further. Briefing paper, Economic Policy Institute.

Cantore, N., M. Clara, A. Lavopa, and C. Soare (2017). Manufacturing as an engine of growth: Which is the best fuel? Structural Change and Economic Dynamics 42, 56 - 66.

Epstein, G. (2001). Financialization, rentier interests, and central bank policy. Technical report, University of Massachusetts, Amherst.

Epstein, G. and J. Schor (1990). Macropolicy in the rise and fall of the Golden Age. In S. A. Marglin and J. B. Schor (Eds.), The Golden Age of Capitalism: Reinterpreting the Postwar Experience, pp. 126-152. Oxford: Clarendon Press.

Felipe, J. and A. Mehta (2016). Deindustrialization? a global perspective. Economics Letters 149, 148-151.

Hersh, A. S. (2003). Is there a future for manufacturing? the visible hand of U.S. deindustrialization. In A. E. Eaton (Ed.), Industrial Relations Research Association: Proceedings of the 55th Annual Meeting, pp. 141-147. Industrial Relations Research Association.

Kaldor, N. (1960). Causes of Growth and Stagnation in the World Economy. Cambridge: Cambridge University Press.

McCombie, J. and A. Thirlwall (1994). Economic Growth and the Balance-of-Payments Constraint. London: Macmillan.

McCombie, J. S. (2011). Criticisms and defences of the balance-of-payments constrained growth model: some old, some new. PSL Quarterly Review 64(259), 353-392.

Missio, F., R. A. Araujo, and F. G. Jayme (2017). Endogenous elasticities and the impact of the real exchange rate on structural economic dynamics. Structural Change and Economic Dynamics 42, $67-75$. 
Nell, K. (2003). A 'generalised' version of the balance-of-payments growth model: An application to neighbouring regions. International Review of Applied Economics 17(3), 249-267.

Nishi, H. (2016). A multi-sectoral balance-of-payments-constrained growth model with sectoral heterogeneity. Structural Change and Economic Dynamics 39, 31 - 45.

Palley, T. (2003). The over-valued dollar abd the US slump. In C. F. Bergsten and J. Williamson (Eds.), Dollar Overvaluation and the World Economy. Washington, DC: Institute for International Economics.

Palley, T. (2016). A theory of economic policy lock-in and lock-out via hysteresis: Rethinking economists' approach to economic policy. Economics Discussion Papers 2016-50, Kiel Institute for the World Economy (IfW).

Razmi, A. (2011). Exploring the robustness of the balance of payments-constrained growth idea in a multiple good framework. Cambridge Journal of Economics 35(3), 545-567.

Rowthorn, B. and J. Wells (1987). De-Industrialization and Foreign Trade. Cambridge: Cambridge University Press.

Schoder, C. (2012). Hysteresis in the Kaleckian growth model: a Bayesian analysis for the US manufacturing sector from 1984 to 2007. Metroeconomica 63(3), 542-568.

Setterfield, M. (2009). Path dependency, hysteresis and macrodynamics. In P. Arestis and M. Sawyer (Eds.), Path Dependency and Macroeconomics (International Papers in Political Economy 2009), pp. 37-79. London: Palgrave Macmillan.

Setterfield, M. (2011). The remarkable durability of Thirlwall's law. PSL Quarterly Review 64 (259), 393-427.

Singh, A. (1977). UK industry and the world economy: a case of de-industrialisation? Cambridge Journal of Economics 1(2), 113-136.

Thirlwall, A. P. (1979). The balance of payments constraint as an explanation of international growth rate differences. Banca Nazionale del Lavoro Quarterly Review 32(128), 45-53.

Thirlwall, A. P. (1983). A plain man's guide to Kaldor's growth laws. Journal of Post Keynesian Economics 5(3), 345-358.

Thirlwall, A. P. (2011). Balance of payments constrained growth models: history and overview. PSL Quarterly Review 64(259), 307-351.

Thirlwall, A. P. (2013). Economic growth in an open developing economy: the role of structure and demand. Cheltenham, UK: Edward Elgar.

Uemura, H. and S. Tahara (2015). De-industrialization in Japan and international production linkages in East Asia. Technical report, presented at the Colloque International Recherche \& Régulation, 10-12 June, Paris. 